\title{
ATUALIZAÇÃO EM INFECÇÕES EM PRÓTESES ARTICULARES
}

\section{UPDATE ON INFECTIONS IN ARTICULAR PROSTHESIS}

Ana Lucia Lei Munhoz Lima', Priscila Rosalba Domingos de Oliveira ${ }^{2}$

\section{RESUMO}

O implante de próteses articulares, principalmente de quadril e joelho, vem se tornando cada vez mais frequente, representando significante redução no desconforto e imensurável melhora na mobilidade dos pacientes. As revisões da literatura mundial revelam que 1 a 5\% destas próteses tornam-se infectadas, sendo importante lembrar que, conforme cresce o número de cirurgias para implantação destas próteses, cresce também o número de casos deste tipo de infecção. As bactérias gram-positivas são predominantes nas contaminações das próteses articulares, em especial o Staphylococcus aureus e o Staphylococcus epidermidis. As infecções causadas por bacilos gram-negativos e fungos como Candida sp vêm sendo relatadas com maior frequência em todo o mundo. As infecções de próteses articulares apresentam sinais característicos que podem ser divididos em manifestações agudas (dor severa, febre alta, toxemia, calor, rubor e secreção na ferida operatória) e crônicas (dor progressiva, formação de fístulas cutâneas, com drenagem de secreção purulenta, sem febre). O diagnóstico definitivo da infecção deve ser realizado através do isolamento em cultura do micro-organismo obtido a partir da punção do líquido articular, secreção da ferida cirúrgica e materiais colhidos durante desbridamento cirúrgico. É fundamental a cobertura de S.aureus meticilinoresistente, visto a importância epidemiológica deste agente nessas infecções. O tempo total da antibioticoterapia varia de seis semanas a seis meses, sendo que o tratamento deve ser readequado quando necessário, com base nos resultados das culturas colhidas.

Descritores - Prótese Articular; Infecção/diagnóstico; Infecção/ terapia

\section{ABSTRACT}

The implantation of artificial joints, especially the hip and knee, is becoming increasingly common, representing a significant reduction in discomfort and an immeasurable improvement in patient mobility. Reviews of the global literature indicate that $1-5 \%$ of these grafts become infected, though it is important to remember that, as the number of surgeries for implantation of these prosthesis grows, so will the number of cases of this type of infection. Gram-positive bacteria predominate in the contamination of joint prosthesis, in particular Staphylococcus aureus and Staphylococcus epidermidis. Infections caused by gramnegative bacilli and fungi such as Candida sp have been reported with increased frequency throughout the world. Infections of joint prosthesis have characteristic signals that can be divided into acute (severe pain, high fever, toxemia, heat, redness, and wound secretion) and chronic (progressive pain, cutaneous fistula formation, with pus drainage, no fever) manifestations. The definitive diagnosis of the infection should be made through the isolation in culture of the micro-organism obtained from the puncture of the joint fluid, surgical wound secretion, and material collected during surgical debridement. It is essential to cover methicillin-resistant Staphylococcus aureus, given the epidemiological importance of this agent in these infections. The total time of antibiotic therapy varies from six weeks to six months, and that treatment should be adjusted as needed, based on the results of culturing.

Keywords - Joint Prosthesis; Infection/diagnosis; Infection/ therapy

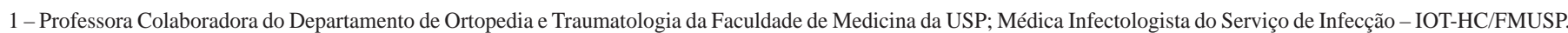
2 - Médica Infectologista do Serviço de Infecção - IOT-HC/FMUSP.
}

Trabalho realizado no Serviço de Infecção do Instituto de Ortopedia e Traumatologia do HC/FMUSP.

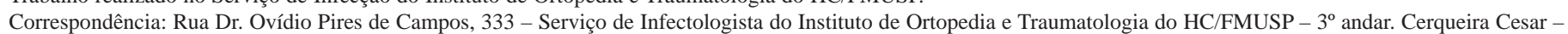
São Paulo, SP. E-mail: ccih.iot@hcnet.usp.br

Trabalho recebido para publicação: 04/08/10, aceito para publicação: 04/08/10. 


\section{INTRODUÇÃO}

O implante de próteses articulares, principalmente de quadril e joelho, vem se tornando cada vez mais frequente, representando significante redução no desconforto e imensurável melhora na mobilidade dos pacientes $^{(1,2)}$. Estima-se que a cada ano ocorram, entre cirurgias primárias e de revisão, cerca de 800 mil cirurgias de implante de próteses de quadril e joelho apenas nos EUA ${ }^{(3)}$ (Figura 1). Embora sejam realizadas em menor número, também estão se tornando mais frequentes as implantações de próteses articulares de ombro, cotovelo, punho e articulação temporomandibular ${ }^{(2)}$. As revisões da literatura mundial revelam que 1 a $5 \%$ destas próteses tornam-se infectadas, sendo importante lembrar que, conforme cresce o número de cirurgias para implantação destas próteses, cresce também o número de casos deste tipo de infecção ${ }^{(4)}$ (Figura 2). Apesar de menos frequente que a perda mecânica, a infecção é considerada a mais devastadora das complicações, acarretando internações prolongadas, intervenções cirúrgicas repetidas e até a perda definitiva do implante, com encurtamento do membro afetado e deformidades importantes e permanentes ${ }^{(1,2)}$.

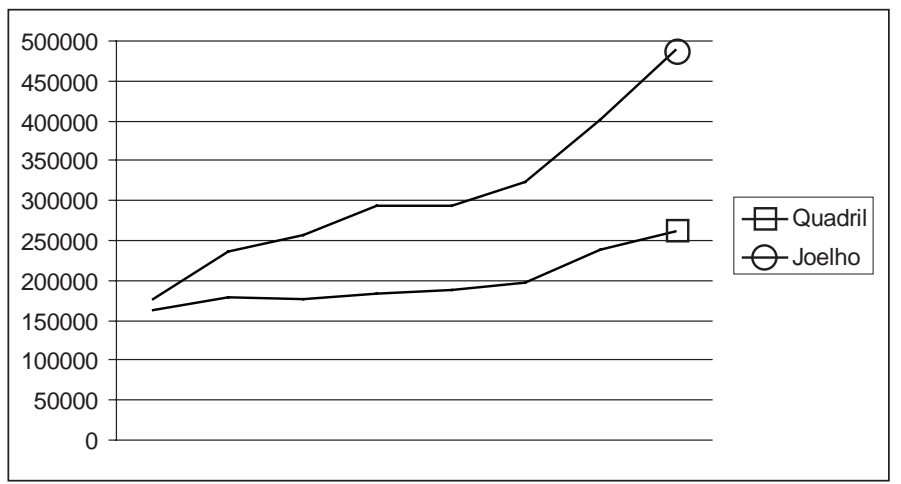

Adaptado de: Kurtz et $a^{\left({ }^{(3)} \text {. }\right.}$

Figura 1 - Evolução do número de próteses de joelho e quadril implantadas nos EUA entre 1990 e 2004.

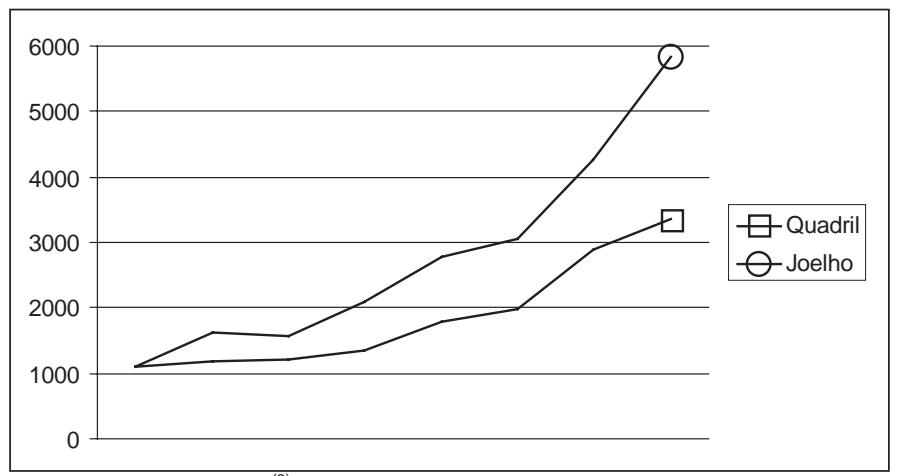

Adaptado de: Kurtz et $a^{\left({ }^{3}\right)}$.

Figura 2 - Evolução do número de infecções em próteses diagnosticadas nos EUA entre 1990 e 2004.

\section{Fatores de risco e fisiopatogenia}

Os principais fatores predisponentes para tal complicação citados na literatura são: idade avançada, desnutrição, obesidade, diabetes melito, infecção pelo HIV em estágio avançado, presença de foco infeccioso à distância e antecedente de artroscopia ou infecção em artroplastia prévia. Pacientes portadores de artrite reumatoide ou psoriática também têm maiores riscos de infecção pós-operatória, sendo estimado em três a oito vezes maior que em outros pacientes. Tempo cirúrgico prolongado (superior a 150 minutos), transfusão sanguínea e realização de artroplastia bilateral em um mesmo tempo cirúrgico são outros fatores relacionados a maior ocorrência de infecção. Qualquer fator que retarde a cicatrização da ferida cirúrgica como necrose isquêmica, hematoma, celulite ou abscesso de ferida, aumenta o risco de infecção, uma vez que os tecidos profundos contíguos à prótese estão desprovidos das barreiras locais de defesa ${ }^{(1,2,4)}$. É importante salientar que a presença da prótese articular leva a um prejuízo da função dos granulócitos locais, que se acumulam ao redor do implante e são parcialmente degranulados, com diminuição na produção de superóxido desmutase e prejuízo na capacidade de defesa contra bactérias, particularmente contra Staphylococcus aureus. Assim, a presença do implante diminui em mais de 100.000 vezes o tamanho do inóculo bacteriano necessário para que ocorra infecção ${ }^{(5)}$.

As próteses articulares podem ser infectadas através de três vias distintas: implantação direta, hematogênica e reativação de infecção latente ${ }^{(2)}$.

A penetração de micro-organismos na ferida durante a cirurgia pode ocorrer a partir de fontes endógenas e exógenas. São exemplos a microbiota cutânea do paciente, dos membros da equipe cirúrgica; o ambiente; e até implantes contaminados.

As bacteremias, a partir de focos à distância, podem gerar contaminação da prótese por via hematogênica. Os focos primários mais frequentemente relatados na literatura mundial são: trato respiratório, cutâneo, urinário, dentário e gastrointestinal ${ }^{(2,5)}$.

As bactérias gram-positivas são predominantes nas contaminações das próteses articulares, em especial o Staphylococcus aureus e o Staphylococcus epidermidis. As infecções causadas por bacilos gram-negativos e fungos como Candida sp vêm sendo relatadas com maior frequência em todo o mundo ${ }^{(5)}$. 


\section{Apresentações clínicas e diagnóstico}

As infecções de próteses articulares apresentam sinais característicos que podem ser divididos em manifestações agudas como dor intensa, febre alta, toxemia, calor, rubor e secreção na ferida operatória ou crônicas, a saber, dor progressiva, formação de fístulas cutâneas, com drenagem de secreção purulenta, na maioria dos casos sem febre. A apresentação clínica depende da virulência do agente etiológico envolvido, da natureza do tecido infectado e da via de aquisição da infecção. Várias classificações foram propostas para definir o momento em que a contaminação ocorre e com isto estabelecer o provável agente etiológico envolvido e a melhor estratégia terapêutica ${ }^{(1,2,5)}$.

Os exames laboratoriais inespecíficos como leucograma, velocidade de hemossedimentação, alfa 1 glicoproteína ácida e proteína $\mathrm{C}$ reativa podem auxiliar o diagnóstico ${ }^{(2)}$.

As alterações radiográficas podem ser semelhantes àquelas encontradas nas perdas mecânicas, não contribuindo para o diagnóstico de infecção. A ultrassonografia pode ser útil na localização de coleções mais profundas e orientação para punção diagnóstica. Os métodos cintilográficos são considerados mais específicos no diagnóstico diferencial principalmente quando utilizadas as técnicas de leucócitos ou imunoglobulinas marcadas com radioisótopos ${ }^{(2)}$.

O diagnóstico definitivo da infecção deve ser realizado através do isolamento em cultura do microorganismo obtido a partir da punção do líquido articular, secreção da ferida cirúrgica e materiais colhidos durante desbridamento cirúrgico ${ }^{(1,2)}$.

\section{Medidas preventivas}

A avaliação pré-operatória dos pacientes candidatos a artroplastia primária é de fundamental importância na prevenção de infecções pós-operatórias visando identificar e tratar focos quiescentes de infecção, bem como estabilizar as comorbidades e reduzir, quando possível, o uso de drogas imunodepressoras. Além deste cuidado, são recomendados ${ }^{(6)}$ :

- internação próxima ao ato cirúrgico;

- limpeza, esterilização e manuseio muito rigoroso de todos os materiais cirúrgicos a serem utilizados;

- manutenção das condições de limpeza, climatização adequada da sala operatória;

- tricotomia restrita e também próxima a cirurgia utilizando-se cremes depilatórios e não aparelhos cortantes;
- limpeza mecânica do local a ser operado com soluções antissépticas como clorexedine;

- criação de ambiente cirúrgico especial com paramentação diferenciada e opcionalmente uso do fluxo laminar;

- antibioticoprofilaxia adequada, iniciada no período de zero a 60 minutos antes da indução anestésica e mantida por 24 horas;

- controle de temperatura corpórea e glicêmico em todo o perioperatório;

- menor tempo cirúrgico possível com técnica adequada;

- curativos cuidadosos realizados com técnica asséptica;

- mobilização precoce do paciente no pós-operatório.

\section{Tratamento}

O sucesso do tratamento das infecções das próteses articulares depende do extenso desbridamento cirúrgico e da antibioticoterapia adequada e efetiva ${ }^{(2,4)}$. Os quadros infecciosos que se desenvolvem no primeiro ano de pósoperatório são considerados infecções hospitalares e devem ser tratados até os resultados das culturas colhidas em centro cirúrgico com antibióticos que tenham ação na microbiota hospitalar do serviço onde foi realizada a cirurgia. É recomendável o início da antibioticoterapia empírica na indução anestésica, o que evita os riscos ao pacientes decorrentes da manipulação cirúrgica do foco de infecção sem cobertura adequada e não interfere na positividade das culturas colhidas no ato operatório. É fundamental a cobertura de S.aureus meticilino-resistente, visto a importância epidemiológica deste agente nessas infecções ${ }^{(5)}$. O tempo total da antibioticoterapia varia de seis semanas a seis meses, sendo que o tratamento deve ser readequado quando necessário, com base nos resultados das culturas colhidas ${ }^{(1,2,4,8)}$.

Infecções em próteses articulares que se manifestem no período de duas a três semanas após a cirurgia de implantação do material podem ser tratadas inicialmente com limpeza cirúrgica extensa associada a antibioticoterapia com duração de seis semanas ${ }^{(8,9)}$. As infecções que se manifestem após esse período, devido à formação de biofilme e aderência bacteriana ao material implantado, devem ser tratadas com limpeza cirúrgica extensa associada à remoção da prótese articular, que pode ser substituída em um ou dois tempos. Neste caso, o tempo total de administração dos antibióticos é de seis meses ${ }^{(7,10)}$. Os fluxogramas abaixo sintetizam as recomendações atuais no manejo destas infecções (Figuras 3 e 4). 


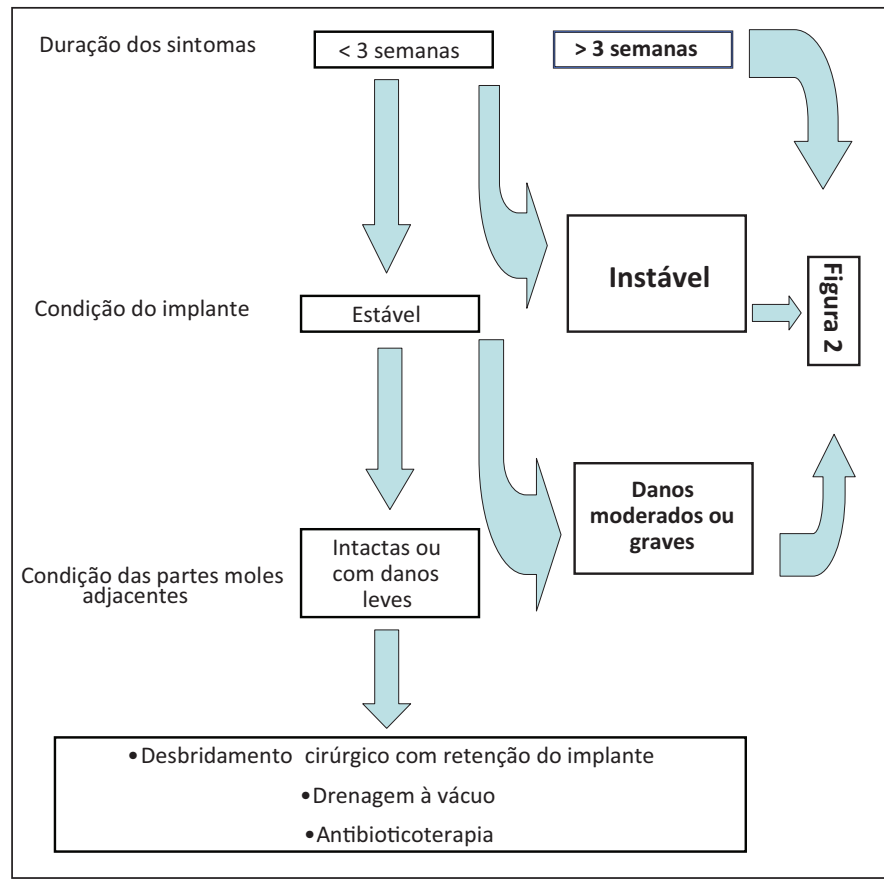

Figura 3 - Conduta nas infecções pós-operatórias agudas em artroplastias.

Os maiores índices de sucesso terapêutico que chegam a 93\% referem-se à retirada da prótese infectada associada a antibioticoterapia prolongada que deverá ser escolhida baseada no agente etiológico isolado na cirurgia de retirada, com posterior implante de nova prótese em segundo tempo cirúrgico, geralmente seis a oito semanas após ${ }^{(7,10)}$. O cimento de polimetilmetacrilato impregnado com gentamicina ou tobramicina pode ser empregado nos reimplantes de próteses após infecções. Em casos de infecções por S.aureus meticilino-resistente, o cimento pode ser impregnado com vancomicina.

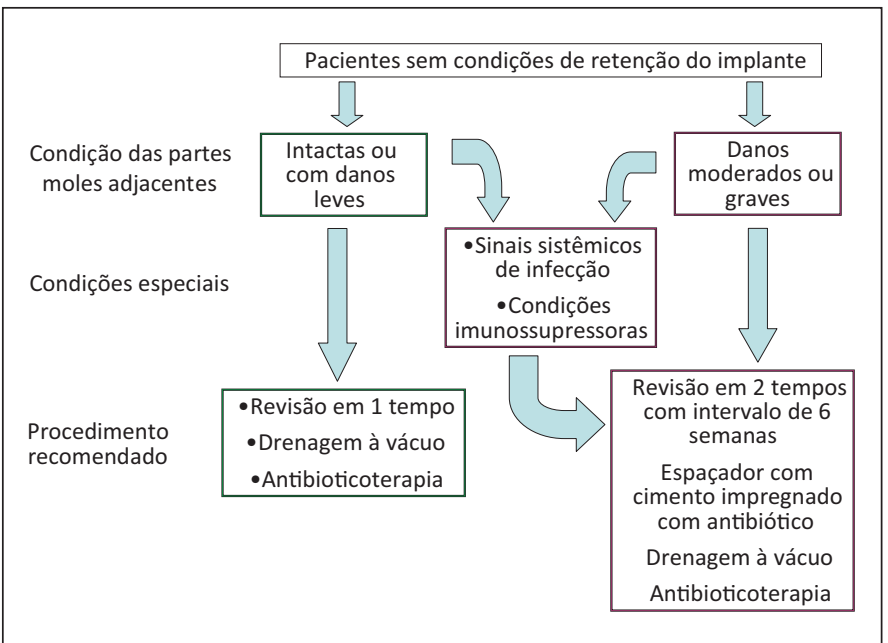

Figura 4 - Conduta nas infecções pós-operatórias em artroplastias com indicação de remoção do implante.

\section{CONSIDERAÇÕES FINAIS}

As infecções em próteses articulares aumentam mundialmente em paralelo ao crescimento de procedimentos realizados. São eventos preocupantes em qualquer uma das apresentações não só pelo potencial de gravidade, mas, também, pelo custo elevado aos pacientes e a todo o sistema de saúde. A ação de fundamental importância a ser adotada na indicação de tais cirurgias, é sempre a prevenção de tais infecções, observando-se criteriosamente todos os fatores que podem contribuir para aumentar o risco dessa complicação. Uma vez que a infecção se estabeleça, o rápido diagnóstico clínico e laboratorial, associado às condutas adequadas contribuem sobremaneira, para aumentar a possibilidade de resolução definitiva do processo.

\section{REFERÊNCIAS}

1. Zimmerli W. Infection and musculoskeletal conditions: Prosthetic-joint-associated infections. Best Pract Res Clin Rheumatol. 2006;20(6):1045-63.

2. Del Pozo JL, Patel R. Clinical practice. Infection associated with prosthetic joints. N Engl J Med. 2009;361(8):787-94.

3. Kurtz SM, Lau E, Schmier J, Ong KL, Zhao K, Parvizi J. Infection burden for hip and knee arthroplasty in the United States. J Arthroplasty. 2008;23(7):984-91.

4. Mortazavi S, Schwartzenberger J, Austin M Purtill J, Parvizi J. Revision Total Knee Arthroplasty Infection. Clin Orthop Relat Res. 2010;(468):2052-9.

5. Frommelt L. Principles of systemic antimicrobial therapy in foreign material associated infection in bone tissue, with special focus on periprosthetic infection. Injury. 2006;37(Suppl 2):S87-94.

6. Mangram AJ, Horan TC, Pearson ML, Silver LC, Jarvis WR. Guideline for prevention of surgical site infection, 1999. Hospital Infection Control Practices Advisory Committee. Infect Control Hosp Epidemiol. 1999;20(4):250-78.

7. Cabrita HB, Croci AT, Camargo OP, Lima AL. Prospective study of the treatment of infected hip arthroplasties with or without the use of an antibiotic-loaded cement spacer. Clinics (Sao Paulo). 2007;62(2):99-108.

8. Estes CS, Beauchamp CP, Clarke HD, Spangehl MJ. A two-stage retention débridement protocol for acute periprosthetic joint infections. Clin Orthop Relat Res. 2010;(468):2029-38.

9. Rudelli S, Uip E, Honda E, Lima ALLM. One-stage revision of infected total hip arthroplasty with bone graft. J Arthroplasty. 2008;23(8):1165-77.

10. Kurd MF, Ghanem E, Steinbrecher J, Parvizi J. Two-stage exchange knee arthroplasty. Clin Orthop Relat Res. 2010;(468):2060-6. 